being taken in hand and thanks to factual information, open discussion, correct use of condoms and widespread testing, the disease has regressed in these groups.

We can learn an important lesson from these changes. Besides ethics known as medical ethics, new ethics which have yet to be given a name have emerged. These ethics will be those of all patients who have learned to handle their own dangerousness either by systematically using prevention or sometimes by changing behaviour patterns and always informing partners. In this way, persons who are neither suffering from AIDS nor seropositive but who nevertheless run the risk of being contaminated will adopt this positive behaviour. The latter group will then handle the AIDS risk in a lucid manner, will not consider AIDS or AIDS carriers as being diabolical, will use the preventive measures recommended everywhere and, in some cases, will opt for sexual monogamy.

DR J M NORES

Assistance Publique - Hopitaux de Paris,

Hopital Raymond Poincare, 104 Bd Raymond Poincare, 92380 GARCHES,

France

\section{Rhetorical devices are of no avail: a rejoinder to Peter Singer}

SIR

Peter Singer has presented an intriguing argument for the opinion that it is quite proper (morally) to deem the lives of certain individuals not worth living and so to kill them. The argument is based on the alleged analogy between the ordinary clinical judgment that a life with a broken leg is worse than a life with an intact leg (other things being equal), and that the broken leg therefore ought to be mended, on the one hand, and the judgment that the lives of some individuals, for example, severely disabled infants, are not worth living and therefore ought to be terminated, on the other. Originally published in 1991 (1), it has recently been reprinted as an appendix to the second, revised edition of Singer's Practical Ethics (2).

I ventured to read, analyze, and criticize his argument (3). I argued that the analogy, and thereby the whole argument, is flawed. I did this very carefully and at some length, since I felt that it is still a remarkable and important argument, the analysis of which may bring some basic differences of moral vision in medical ethics into focus. To this end I discussed, among other things, the existential meaning of death, of existence in the face of non-existence, and I concluded that this seems to be a "blind spot' in Singer.

Singer has responded to my criticism (4). However, he has not responded in the manner you might expect from a philosopher who prides himself on rational argument. He evades argument in the manner of one who has been defeated in argument but is unwilling to admit it. Instead of taking refuge in silence he displays some dissimulating rhetorical devices: 1 . What he says has been said before by his philosophical master, R M Hare; 2 . He never intended to say what he appears to say, and 3. He has said other things elsewhere.

These rhetorical moves may be important to Singer psychologically, $\vec{\Rightarrow}$ but they are of no avail when it comes? to the facts of the matter. Singer's argument has been made public, and $\frac{\bar{\sigma}}{\bar{S}}$ so has my counter-argument. Anyone $\frac{\bar{\rho}}{\partial}$ can read his argument in its published $\mathbb{Q}$ form; it is no longer his private musing, and it is not exclusively tied to whatever ${ }^{\text {s }}$ intentions may have been present in his $\vec{O}$ mind as he wrote it down on paper. And when I analyzed and criticized it, $\omega$ I did not care about Peter Singer's intentions, except as he had made them $\widetilde{\mathbb{D}}^{2}$ public in writing. It is all there in the $N$ book, to be interpreted in context.

But Singer chooses to talk about $\tilde{\omega}$ other things: his intentions, other $\vec{N}$ books, professor Hare. That is a sado spectacle, but revealing ...

\section{References}

(1) Singer P. On being silenced in Germany. The New York review of $\Phi$ books 1991; 38, 14: 34-40.

(2) Singer P. Practical ethics. [2nd, revised ed]. New York: Cambridoge cr University Press, 1993: 355-35\%.

(3) Sundström P. Peter Singer a⿳亠㐅⿵冂卄 'lives not worth living' - corn ments on a flawed argument from analogy. Fournal of medical ethics 1995; 21: 35-38.

(4) Singer P. Straw men with broken $\overrightarrow{\overrightarrow{0}}$ legs: a response to $\operatorname{Per} 3$ Sundström. fournal of medical ethics 1995; 21: 89-90.

PER SUNDSTRÖM, MD PhD,

Lagga, Rosendal, $\div$ S-741 93 Knivsta, Sweden 